Assortative pairing in the amphipod Paracalliope fluviatilis: a role for parasites?

Lefebvre, Francois; Fredensborg, Brian Lund; Armstrong, Amy; Hansen, Ellen; Poulin, Robert

Published in:

Hydrobiologia

Publication date:

2005

Document version

Early version, also known as pre-print

Citation for published version (APA):

Lefebvre, F., Fredensborg, B. L., Armstrong, A., Hansen, E., \& Poulin, R. (2005). Assortative pairing in the amphipod Paracalliope fluviatilis: a role for parasites? Hydrobiologia, 545. 
Primary Research Paper

\title{
Assortative pairing in the amphipod Paracalliope fluviatilis: a role for parasites?
}

\author{
François Lefebvre*, Brian Fredensborg, Amy Armstrong, Ellen Hansen \& Robert Poulin \\ Department of Zoology, University of Otago, P.O. Box 56, Dunedin, New Zealand \\ (*Author for correspondence: E-mail: fr_lefebvre@hotmail.com)
}

Received 10 November 2004; in revised form 26 January 2005; accepted 13 February 2005

Key words: Amphipoda, Trematoda, Coitocaecum parvum, Microphallus sp., reproduction, mate choice

\begin{abstract}
The potential impact of parasitism on pairing patterns of the amphipod Paracalliope fluviatilis was investigated with regard to the infection status of both males and females. Two helminth parasites commonly use this crustacean species as second intermediate host. One of them, Coitocaecum parvum, is a progenetic trematode with an egg-producing metacercaria occasionally reaching $2.0 \mathrm{~mm}$ in length, i.e. more than $50 \%$ the typical length of its amphipod host. The amphipod was shown to exhibit the common reproductive features of most precopula pair-forming crustaceans, i.e. larger males and females among pairs than among singles, more fecund females in pairs, and a trend for size-assortative pairing. Although effects of parasitism were expected a priori, no major influence of the two trematodes was shown on the host reproductive patterns herein investigated. In particular, the occurrence of pairs of infected individuals conformed exactly to what can be expected under the null hypothesis of completely random pair formation. The absence of parasite effect was also illustrated by a similar fecundity of infected and uninfected females. This study thus tends to moderate the widespread view of a strong influence of parasitism on host mating patterns, as suggested by the recent literature on this specific subject.
\end{abstract}

\section{Introduction}

The impact of parasitism on animal mating success has received much attention in recent years. On the one hand, parasitised males are less likely to mate with females for a range of reasons, not mutually exclusive. Parasitised males may be less able to compete with healthy males for access to females (Howard \& Minchella, 1990; Forbes, 1991). Parasitised males may also be less attractive to females because infection reduces the expression of secondary sexual traits such as body colouration or courtship displays (Hamilton \& Zuk, 1982; Zuk, 1992). Females often choose not to mate with parasitised males to avoid becoming infected themselves or, in species with male parental care, because parasitised males are poor fathers (Clayton, 1991; Able, 1996). On the other hand, parasitised females are often less chosen by males, because infection may reduce their attractiveness or decrease their reproductive potential, i.e. lower fecundity, reduced breeding capacity (Baudouin, 1975; Minchella, 1985). Furthermore, infected individuals (both males and females) are often less choosy than healthy ones, because they have less energy to invest in mate assessment or because their ability to discriminate among potential mates is impaired (Poulin, 1994; Poulin \& Vickery, 1996; Lopez, 1999). The net result of these documented effects is that parasites may have an overarching influence on mating combinations within a host population. 
One way to investigate this possibility is to look for assortative mating by infection status, i.e. nonrandom assortment between males and females with respect to whether or not they are parasitised. This has only been done for very few host-parasite systems, involving either trematode or acanthocephalan parasites in gammarid amphipods (Thomas et al., 1995a, b; Bollache et al., 2001, 2002) or protozoan parasites in beetles (Thomas et al., 1999). The results of these studies are generally supportive of a role for parasites in pair formation, but the approach needs to be extended to other systems to verify the generality of the pattern. Here, we investigate the question in the New Zealand amphipod Paracalliope fluviatilis (Thomson, 1879) (Amphipoda: Eusiridae) serving as second intermediate host for the parasite Coitocaecum parvum Crowcroft, 1945 (Trematoda: Opecoelidae).

The reproductive season in the amphipod $P$. fluviatilis begins toward the end of the austral winter, when water temperature increases (F. Wilhelm, unpublished data). Mating with successful egg fertilization is only possible after the female's moult when the cuticle is still soft. Since moulting cycles of females are not synchronised, only some females can mate at any given time, and the operational sex ratio is strongly male-biased at any time during the reproductive season (F. Wilhelm, unpublished data). Males compete by trying to monopolise high value females long before mating may occur (i.e. precopulatory mate guarding). With their modified subchelae, they grab the female from above and form pairs for days, in a position sometimes called amplexus (Sutcliffe, 1992).

The trematode $C$. parvum uses the snail Potamopyrgus antipodarum as first intermediate host, $P$. fluviatilis as second intermediate host, and fish (mainly the common bully Gobiomorphus cotidianus) as definitive hosts (MacFarlane, 1939; Holton, 1984a). Cercariae shed by the snails penetrate amphipods and encyst as metacercariae within the amphipod's hemocoel. Some metacercariae develop into adults while still inside the amphipod intermediate host (MacFarlane, 1939; Holton, 1984b). These progenetic metacercariae produce viable eggs that are retained within the cyst, but can also be found throughout the host's hemocoel if the thin cyst has been ruptured. Thus, there is a range of metacercarial developmental stages that can be found within the amphipod $P$. fluviatilis, from newly encysted metacercariae less than $0.5 \mathrm{~mm}$ long to fully developed progenetic worms occasionally reaching $2 \mathrm{~mm}$ in length, i.e. more than $50 \%$ of the length of a typical amphipod (Lefebvre \& Poulin, 2005).

In a recent study on host manipulation by parasites, Poulin (2001) found no influence of $C$. parvum on either the photophilia or the spontaneous activity of the amphipod P. Aluviatilis. However, given the large size of the parasite relative to its host, one might expect impacts on other aspects of the amphipod biology. The aim of this study is to investigate the parasite's potential influence upon mating patterns of $P$. fluviatilis. Emphasis will be placed on the process of pair formation according to the infection status of both males and females.

\section{Material and methods}

\section{Data collection}

Amphipods were collected from Lake Waihola (40 km south-west of Dunedin, South Island, New Zealand; $46^{\circ} 01^{\prime} \mathrm{S}, 170^{\circ} 05^{\prime} \mathrm{E}$ ) at the end of the austral winter (23 August 2003). Animals were randomly sampled by dragging a dip net through a patch of macrophytes (Myriophyllum triphyllum) at a distance of 5-10 $\mathrm{m}$ from the shore (mean depth approximately $0.5 \mathrm{~m}$ ). For each dip net sample, pairs were immediately picked up and placed in $5 \mathrm{ml}$ vials filled with lake water and a small strand of macrophyte. In the same time, a sub-sample of single individuals (roughly the same number as paired individuals) was collected and placed in a larger container with lake water and macrophytes. The procedure was repeated until approximately 500 pairs had been collected.

In the laboratory, all amphipods were measured to the nearest $0.1 \mathrm{~mm}$ (from the anterior tip of the cephalon to the posterior tip of the telson), sexed, and dissected to look for parasites. Two developmental stages of $C$. parvum were distinguished according to the presence/absence of eggs (either in utero or released into the cyst), and thereafter referred to as progenetic metacercariae or normal metacercariae, respectively. Throughout 
the study, prevalence was defined as the percentage of infected amphipods, abundance as the number of parasites per amphipod whether infected or not, intensity as the number of parasites per infected amphipod, and mean intensity as the mean number of parasites among a sample of infected amphipods (see Bush et al., 1997). For unpaired amphipods, the minimal threshold value for breeding size was determined from the size of the smallest male and female found in the collection of paired individuals. Only males and females of breeding size were considered and later used as comparison with paired animals. For female amphipods, the fecundity was assessed by counting the number of eggs in the brood pouch (i.e. marsupium). The fecundity assessment was done for both males and females, since egg production in this species is spontaneous and may occur in the absence of males. Only females with at least one egg in early development were considered (from newly laid eggs to undifferentiated morula, i.e. stage 1 and stage 2 according to McCahon \& Pascoe, 1988), because older eggs or embryos may be lost by females during handling.

\section{Data analysis}

Though distributed following a bell-shaped curve, data on amphipod size and fecundity did not conform to a normal distribution (Shapiro-Wilks: $p<0.01$ ), and thus non-parametric tests should be applied. However, according to the central theorem limit, a small departure from normality (i.e. skewness: $0 \pm 1$, kurtosis: $0 \pm 3$ ) does not constitute a severe violation to the application of parametric tests in cases of large sample sizes (Sokal \& Rohlf, 1995). Therefore, parametric analyses were used for data on amphipod size and fecundity (independent $t$ tests, Pearson correlations, ANCOVA models). For all other data concerning parasite parameters, non-parametric tests were applied because the departure from the normal distribution was substantial (Mann-Whitney tests, $\chi^{2}$ tests, Spearman rank tests). All statistical treatments were performed using the STATISTICA 6.0 package. Means are given $\pm \mathrm{SE}$ and proportions with $95 \%$ confidence interval in brackets. Throughout the study, statistical results were considered significant at $p<0.05$.

\section{Results}

\section{Mating patterns in Paracalliope fuviatilis}

A total of 463 living pairs of amphipods was investigated. The mean size of paired males was $3.63 \pm 0.02 \mathrm{~mm}$ (range: $2.1-4.6 \mathrm{~mm}$ ) and the mean size of paired females $2.59 \pm 0.01 \mathrm{~mm}$ (range: $1.7-$ $3.5 \mathrm{~mm}$ ) (see Table 1). There was a clear pattern for size assortative pairing $(r=0.27, n=463$, $p<0.001$ ) with large males paired generally with large females and small males with small females (see Fig. 1).

Of the 752 unpaired amphipods randomly collected at the same time, 720 met the minimal threshold value for breeding size (i.e. $>2.0 \mathrm{~mm}$ for males and $>1.6 \mathrm{~mm}$ for females, see Material and

Table 1. Size of males and females of both paired and unpaired amphipods according to their infection status

\begin{tabular}{|c|c|c|c|c|c|c|}
\hline & \multicolumn{6}{|l|}{ Size in $\mathrm{mm}$} \\
\hline & $\begin{array}{l}\text { Infected by } \\
C . \text { parvum } \\
\text { normal stage }\end{array}$ & $\begin{array}{l}\text { Infected by } \\
\text { C. parvum } \\
\text { progenetic stage }\end{array}$ & $\begin{array}{l}\text { Infected by } \\
\text { C. parvum } \\
\text { both stages }\end{array}$ & $\begin{array}{l}\text { Infected by } \\
\text { Microphallus sp. }\end{array}$ & Not infected & All \\
\hline \multicolumn{7}{|c|}{ Paired amphipods } \\
\hline$\hat{o}$ & $3.73 \pm 0.03(65)$ & $3.78 \pm 0.08(23)$ & $3.72 \pm 0.04(78)$ & $3.72 \pm 0.06(30)$ & $3.61 \pm 0.02(358)$ & $3.63 \pm 0.02(463)$ \\
\hline ㅇ & $2.71 \pm 0.06$ & $2.76 \pm 0.12(9)$ & $2.67 \pm 0.05$ & $2.74 \pm 0.07(14)$ & $2.58 \pm 0.014(415)$ & $2.59 \pm 0.01(463)$ \\
\hline \multicolumn{7}{|c|}{ Unpaired amphipods } \\
\hline$\hat{\jmath}$ & $3.49 \pm 0.10(20)$ & $3.57 \pm 0.14(10)$ & $3.51 \pm 0.09(27)$ & $3.26 \pm 0.09(27)$ & $2.89 \pm 0.03(260)$ & $2.97 \pm 0.03(309)$ \\
\hline q & $2.64 \pm 0.06(17)$ & $2.72 \pm 0.08(8)$ & $2.66 \pm 0.05(24)$ & $2.60 \pm 0.05$ & $2.38 \pm 0.02(378)$ & $2.39 \pm 0.02(411)$ \\
\hline
\end{tabular}

The number of amphipods in each category is given in parentheses after mean size values. 


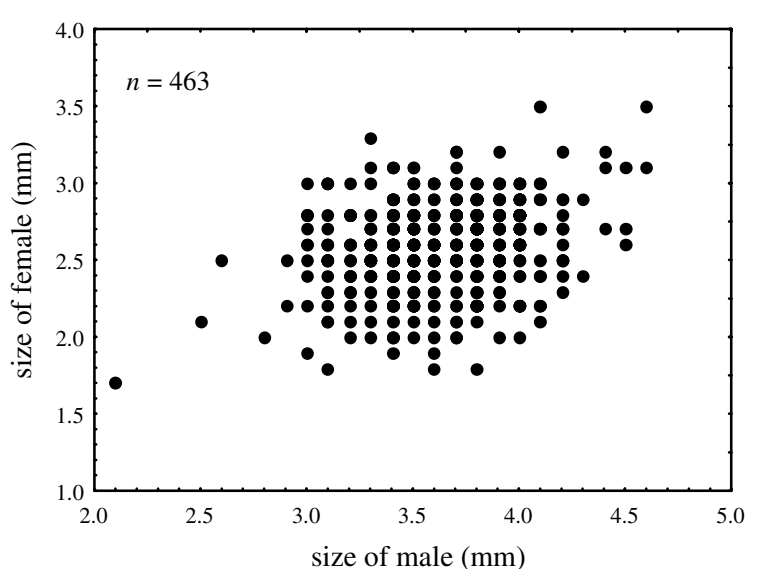

Figure 1. Relationship between male and female size among pairs of the amphipod Paracalliope fluviatilis.

methods section). The proportion of males among this sub-sample of single amphipods was 43\% [3947] (309 males vs. 411 females).

The size of paired males significantly differed from the size of unpaired males $(t=21.01$, $\mathrm{df}=770, p<0.001)$. Paired males were on average $22 \%$ larger than unpaired ones (see Table 1). Similarly, paired females significantly differed in size from unpaired females $(t=8.64$, $\mathrm{df}=872, p<0.001)$. Paired females were on average $8 \%$ larger than single ones (see Table 1 ).

Regarding female fecundity, there was an overall significant positive relationship between female size and their number of eggs (for both paired and unpaired females with at least one egg in the marsupium: $r=0.36, n=471, p<0.001$ ). In an ANCOVA model, no interaction was found between size and pairing status $(F=0.54$, df $=467, p=0.46$ ), but a significant difference was revealed between the fecundity of paired and unpaired females $(F=12.87$, df $=468, p<0.001)$. As shown in Figure 2, paired females tend to have more eggs than single ones (for a covariate mean value of $2.60 \mathrm{~mm}$, respectively $6.12 \pm 0.12$ eggs and $5.42 \pm 0.15$ eggs, i.e. $+13 \%)$.

\section{Trematode infection and pairing status}

Prevalence and mean parasite intensity for both paired and unpaired males and females are given in Table 2. Infection parameters of C. parvum are presented separately for both normal and progenetic stages of the worm. However, data were later

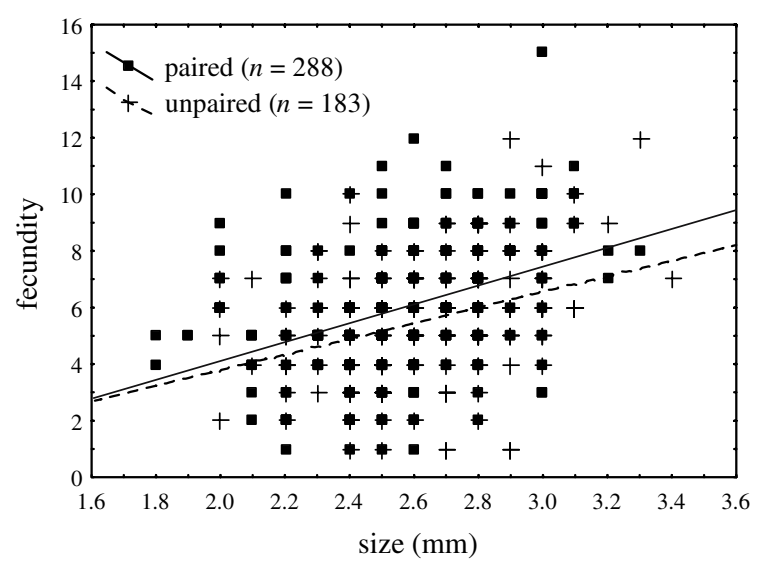

Figure 2. Relationship between size and fecundity for paired and unpaired females of the amphipod Paracalliope fluviatilis.

pooled since no significant difference was observed between these 2 developmental stages with regard to their effect on host reproduction. Overall, the prevalence in $C$. parvum for both paired and unpaired males and females was $167 / 1646=10.15 \%$ [8.69-11.61], and the mean intensity was $1.46 \pm 0.07$. Moreover, in the course of dissection, a second parasite species was found in the host hemocoel and identified as a trematode of the genus Microphallus (Microphallidae). Instead of removing all Microphallus-infected amphipods from the sample, this second trematode was also considered in the analyses. It is characterised by a spherical metacercaria surrounded by a thick double-layered cyst, with an external average diameter of $0.2 \mathrm{~mm}$. Overall, the prevalence in Microphallus sp. for both paired and unpaired males and females was $81 / 1646=4.92 \%$ [3.885.97], and the mean intensity was $1.07 \pm 0.03$.

Paired males had a higher prevalence in C. parvum than unpaired males ( $78 / 385$ vs. $27 / 282$ : $\chi^{2}=10.37$, df $\left.=1, p<0.01\right)$. This could be because paired males were an average larger (as mentioned above), since prevalence in $C$. parvum tends to increase with male size $\left(r_{\mathrm{s}}=0.22\right.$, $n=772, p<0.001)$. No difference was observed with respect to mean parasite intensity between paired and unpaired males ( $z$ adjusted for ties $=0.04, p=0.97)$. In females, prevalence in $C$. parvum did not differ between paired and unpaired ones $\left(38 / 425\right.$ vs. $24 / 387: \chi^{2}=1.85$, df $=1$, $p=0.17)$ and the same was observed for mean intensity ( $z$ adjusted for ties $=1.05, p=0.29$ ). 


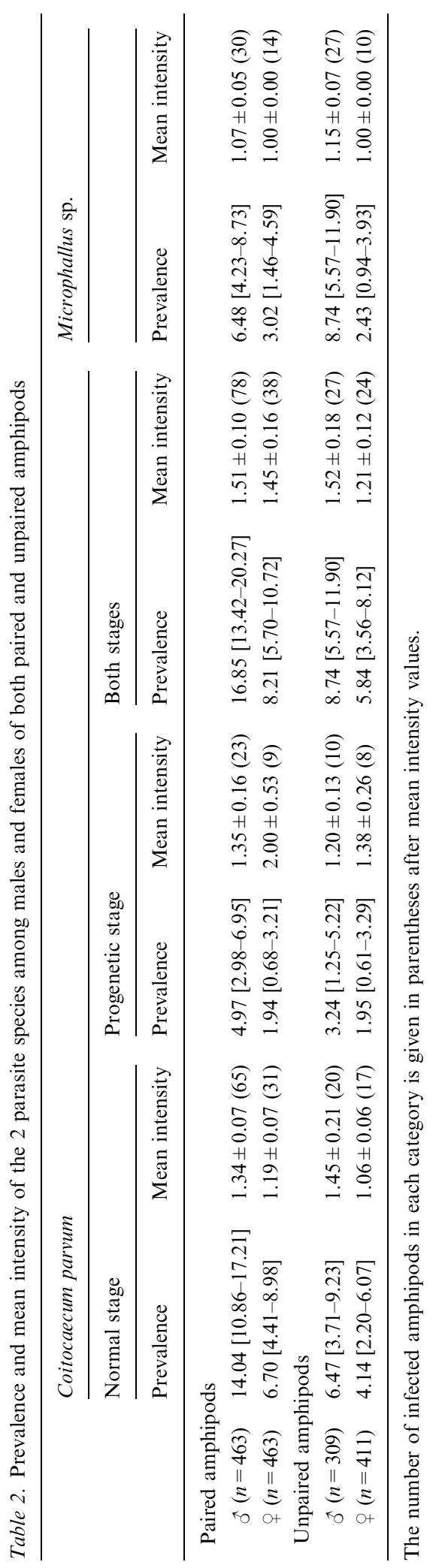


Table 3. Observed and expected number of pairs for each possible combination of infection status between male and female amphipods

\begin{tabular}{cllll}
\hline & UU & UI & IU & II \\
\hline $\begin{array}{c}\text { C. parvum } \\
\text { Observed }\end{array}$ & 353 & 32 & 72 & 6 \\
$\begin{array}{c}\text { Expected } \\
\text { Microphallus sp. }\end{array}$ & 353.40 & 31.60 & 71.60 & 6.40 \\
$\begin{array}{l}\text { Observed } \\
\text { Expected }\end{array}$ & 420 & 13 & 29 & 1 \\
Both trematodes & 419.91 & 13.09 & 29.09 & 0.91 \\
Observed & 322 & 36 & 93 & 12 \\
Expected & 320.89 & 37.11 & 94.11 & 10.89 \\
\hline
\end{tabular}

UU: uninfected male/uninfected female, UI: uninfected male/ infected female, IU: infected male/uninfected female, II: infected male/infected female. Expected values are computed under the hypothesis of random pairing by using the observed infection rate of males and females for any given parasite (see Table 2).

For Microphallus sp., there was no difference between paired and unpaired males in either prevalence $\left(30 / 433\right.$ vs. $27 / 282: \chi^{2}=1.38, \mathrm{df}=1$, $p=0.24)$, or mean intensity $(z$ adjusted for ties $=0.99, p=0.32)$. In females, prevalence did not differ between paired and unpaired ones (14/ 449 vs. $10 / 401: \chi^{2}=0.28$, df $=1, p=0.59$ ), and similarly, no difference was observed for mean parasite intensity $(z=0.00, p=1.00)$.

\section{Trematode infection and partner size}

Pearson coefficients from male size vs. female size correlations did not differ when comparing uninfected males and infected ones (for C. parvum: $r=0.27, n=385$ and $r=0.26, n=78$, two-sided test: $p=0.93$; for Microphallus sp.: $r=0.28$, $n=433$ and $r=0.18, n=30$, two-sided test: $p=0.59$; both trematodes: $r=0.28, n=358$ and $r=0.24, n=105$, two-sided test: $p=0.70$ ). Thus, the infection status of males did not seem to influence the size of females with which they can pair. The same pattern was observed when only considering infection-free females as partners (for each trematode or for both together, in all cases: $p>0.88$ ).

In contrast, a difference in the Pearson coefficients from male size vs. female size was revealed between uninfected and infected females (for C. parvum: $r=0.23, n=425$ and $r=0.55$, $n=38$, two-sided test: $p<0.05$; for Microphallus sp.: $r=0.26, n=449$ and $r=0.50, n=14$, twosided test: $p=0.35$; both trematodes: $r=0.23$, $n=415$ and $r=0.54, n=48$, two-sided test: $p<0.05$ ). Infection of females by $C$. parvum did influence the size of their pairing males. This was also observed when only considering infection-free males (for C. parvum: $r=0.23, n=329$ and $r=$ $0.61, n=29$, two-sided test: $p<0.05$ ). In comparison to uninfected females, small females infected by C. parvum had smaller males and large infected ones had larger males.

\section{Trematode infection and assortative pairing}

Observed and expected numbers of pairs for each possible combination of infection status between males and females are shown in Table 3. Among the 463 pairs, the null hypothesis of random pairing according to the presence/absence of parasites cannot be rejected for either of the two trematodes (for C. parvum: $\chi^{2}=0.03, \mathrm{df}=3$, $p=1.00 ;$ for Microphallus sp.: $\chi^{2}=0.01$, $\mathrm{df}=3, p=1.00)$. Observed and expected numbers of pairs remained almost identical even when considering infection by both trematode species $\left(\chi^{2}=0.16\right.$, df $\left.=3, p=0.98\right)$.

With regard to parasite abundance, there was no significant relationship between male and female within pairs (for $C$. parvum: $r_{\mathrm{s}}=0.00$, $n=463, p=0.95$; for Microphallus sp.: $r_{s}=0.01$, $n=463, p=0.87$; for both trematodes: $r_{\mathrm{s}}=0.03$, $n=463, p=0.55$ ).

\section{Trematode infection and female fecundity}

In an ANCOVA model on the female fecundity (paired and unpaired altogether), no significant interaction was found between size and infection status (for C. parvum: $F=0.73$, df $=467$, $p=0.39 ;$ for Microphallus sp.: $F=1.47$, $\mathrm{df}=467, \quad p=0.22 ; \quad$ for both trematodes: $F=2.87, \mathrm{df}=467, p=0.09$ ). For any of the 2 trematodes, the infection status had no effect on female fecundity (for $C$. parvum: $F=0.59$, df $=468, \quad p=0.44 ; \quad$ for Microphallus sp.: $F=0.37, \mathrm{df}=468, p=0.54$; for both trematodes: $F=0.69, \mathrm{df}=468, p=0.41$ ). 
Among infected females, no correlation was detected between fecundity and parasite intensity for either of the 2 trematodes (for $C$. parvum: $r_{\mathrm{s}}=0.07, n=36, p=0.70$; for Microphallus sp.: no possible test since intensity was $1.00 \pm 0.00$; for both trematodes together: $r_{\mathrm{s}}=0.07, n=45$, $p=0.65)$.

\section{Discussion}

In the investigated sample of Paracalliope $f l u$ viatilis, the sex-ratio was slightly but significantly female biased $(43 \%$ of males among single individuals of breeding size). However, as for most amphipod species (Sutcliffe, 1993), the mating period for females is restricted to a few hours after the moult, whereas males are supposedly ready to mate at any time (with the exclusion of the ecdysis period). This inevitably results in a strong male-biased operational sexratio, a condition under which an intense malemale competition is expected (Kvarnemo \& Ahnesjö, 1996).

The results reported here tend to support this prediction with a selective advantage of larger males for access to reproductive females. Paired males were on average $22 \%$ larger than unpaired ones. An advantage of large size seems also to occur in females, with paired females on average $8 \%$ larger than single ones. Since there is a positive relationship between size and fecundity $(r=0.36)$, paired females also produced more eggs than unpaired ones $(+13 \%)$.

Within pairs, males and females tend to be matched for size. This pattern of pairing in Paracalliope fluviatilis was already noted by F. Wilhelm (unpublished data) in samples collected from the same lake. In such size assortment, larger males are found with larger females and smaller males with smaller females. This feature is now a welldocumented characteristic of most amphipod species (see Sutcliffe, 1993) and also many isopods (see Jormalainen, 1998). Although various hypotheses have been advanced to explain assortative pairing by size in amphipods (loading constraint: Adams \& Greenwood, 1983; spatial segregation: Birkhead \& Clarkson, 1980; sexual selection: Ward, 1984; guarding time: Elwood et al., 1987; see Crespi, 1989 for review), one of the most widely accepted view involves a large male advantage in the male-male competition for access to larger, more fecund females (for a recent issue, see Bollache \& Cézilly, 2004).

In the last few years, some studies have documented a crucial role for parasites in male and female assortment into precopula pairs (Thomas et al., 1995b, 1996; Bollache et al., 2001, 2002). In such cases, positive assortative pairing by parasite load was reported, with infected males more often associated with infected females than would be expected by chance alone. Non-random pairing with respect to infection is likely to be observed in case of severe adverse effect of the parasites on their host (i.e. parasite induced depletion of host energy reserve, parasite mediated change in host behaviour).

The progenetic trematode Coitocaecum parvum is one of those parasites that are strongly expected to alter the biology of their hosts. After several weeks of infection, metacercariae grow from 0.5 to $1.0 \mathrm{~mm}$, some of them becoming egg-producing worms of nearly $2.0 \mathrm{~mm}$ (overall proportion of progenetic forms: $30 \%$ in the present sample) (Holton, 1984a; Lefebvre \& Poulin, 2005). Fully developed metacercariae may thus fill the host body cavity and in extreme cases deform the general shape of the infected amphipod. Though little is known about its biology, $C$. parvum growth and egg production (up to 500 eggs, mean number of 140 released eggs, see Lefebvre \& Poulin, 2005) are most likely achieved at the expense to the host's energy reserve. This parasite is here reported at a prevalence of $10 \%$ among all breeding size amphipods. In addition, a second trematode species, Microphallus sp., was documented in the hemocoel of $5 \%$ of all breeding size amphipods. Interestingly, in another trematode-amphipod system, a Microphallus species is responsible for clear-cut assortative pairing by parasite infection (Thomas et al., 1995b, 1996).

In the present study, although strongly expected, no major impact of parasitism was detected. The only documented effect concerned a change in the average size of the pairing male in case of female infection by $C$. parvum. In comparison to uninfected females, small females infected by $C$. parvum had smaller males and large infected ones had larger males. This may be due to the increased female weight in case of infection, 
since large females generally harboured large eggproducing worms. For all the other aspects of reproduction herein investigated, no impact of parasitism was revealed. The number of infected pairs conformed exactly to what could be expected under the null hypothesis of completely random pair formation. In the same way, infection by any of the two parasites did not reduce the female fecundity. Whether parasites decrease the male's competitiveness was not addressed here, but if any reduction in the male vigour occurs (see Rumpus \& Kennedy, 1974), this does not greatly affect the pair formation process.

The results of the present study thus conform to the experiments of Ward (1986), Poulton \& Thompson (1987) and Thomas et al. (1995a) showing that amphipod males did not pair less frequently with infected females. In contrast, this departs from the more recently documented cases in which parasitism has been shown to significantly alter pair formation in amphipods (Thomas et al., 1995b; Bollache et al., 2001, 2002).

Thus, one must be cautious when assessing the generality of a biological pattern by searching the scientific literature because of the trend for publishing only significant results (see Jennions \& Møller, 2002; Koricheva, 2003). In the present case, a review of the recent literature suggests that parasitism has a strong influence on pair formation in amphipod host species. This is probably far from a universal rule, however. One needs to further consider the physiological and behavioural impacts of the infection before expecting any influence on host mating patterns.

From the above studies on amphipod species, it appears that parasite alteration of pair formation is often associated with either behavioural manipulation (Thomas et al., 1995b, 1996; Bollache et al., 2001, 2002), reduced survival (Thomas et al., 1995b) or drastically reduced fecundity (Ward, 1986; Thomas et al., 1995b; Bollache et al., 2002). So far, no such effects have been reported for C. parvum (see Poulin, 2001), and nothing is known for the Microphallus species found in this study. When no physiological or behavioural effect results from the infection, one should rather expect no consequence on the host pairing process (as in Thomas et al., 1995a, and the present study).

\section{Acknowledgements}

During this study, F. L. was funded by the foundation Basler Stiftung für Biologische Forschung (Basel, Switzerland), B. F. and E. H. by the Marsden Foundation (Wellington, New Zealand). We thank Dr Sergio Martorelli (CEPAVE, Argentina) for confirming our identification of Microphallus sp., and Dr Frank Wilhelm (Southern Illinois University, USA) for communication of unpublished data about host biology.

\section{References}

Able, D. J., 1996. The contagion indicator hypothesis for parasite-mediated sexual selection. Proceedings of the National Academy of Sciences USA 93: 2229-2233.

Adams, J. \& P. Greenwood, 1983. Why are males bigger than females in precopula pairs of Gammarus pulex? Behavioral Ecology and Sociobiology13239241.

Baudouin, M., 1975. Host castration as a parasitic strategy. Evolution 29: 335-352.

Birkhead, T. R. \& K. Clarkson, 1980. Mate selection and precopulatory guarding in Gammarus pulex. Zeitschrift für Tierpsychologie 52: 365-380.

Bollache, L. \& F. Cézilly, 2004. Sexual selection on male body size and assortative pairing in Gammarus pulex (Crustacea: Amphipoda): field surveys and laboratory experiments. Journal of Zoology 264: 135-141.

Bollache, L., G. Gambade \& F. Cézilly, 2001. The effects of two acanthocephalan parasites, Pomphorhynchus laevis and Polymorphus minutus, on pairing success in male Gammarus pulex (Crustacea: Amphipoda). Behavioral Ecology and Sociobiology 49: 296-303.

Bollache, L., T. Rigaud \& F. Cézilly, 2002. Effects of two acanthocephalan parasites on the fecundity and pairing status of female Gammarus pulex (Crustacea: Amphipoda). Journal of Invertebrate Pathology 79: 102-110.

Bush, A. O., K. D. Lafferty, J. M. Lotz \& A. W. Shostak, 1997. Parasitology meets ecology on its own terms: Margolis et al. revisited. Journal of Parasitology 83: 575-583.

Clayton, D. H., 1991. The influence of parasites on host sexual selection. Parasitology Today 7: 329-334.

Crespi, B. J., 1989. Causes of assortative mating in arthropods. Animal Behaviour 38: 980-1000.

Elwood, R. W., J. Gibson \& S. Neil, 1987. The amorous Gammarus: size-assortative mating in G. pulex. Animal Behaviour 35: 1-6.

Forbes, M. R. L., 1991. Ectoparasites and mating success of male Enallagma ebrium damselflies (Odonata: Coenagrionidae). Oikos 60: 336-342.

Hamilton, W. D. \& M. Zuk, 1982. Heritable true fitness and bright birds: a role for parasites? Science 218: 384-387.

Holton, A. L., 1984a. A redescription of Coitocaecum parvum Crowcroft, 1945 (Digenea: Allocreadiidae) from crustacean and fish hosts in Canterbury, previously misidentified as 
Coitocaecum anaspidis Hickman, 1934. New Zealand Journal of Zoology 11: 1-8.

Holton, A. L., 1984b. Progenesis as a means of abbreviating life histories in two New Zealand trematodes, Coitocaecum parvum Crowcroft, 1945 and Stegodexamene anguillae MacFarlane, 1951. Mauri Ora 11: 63-70.

Howard, R. D. \& D. J. Minchella, 1990. Parasitism and mate competition. Oikos 58: 120-122.

Jennions, M. D. \& A. P. Møller, 2002. Publication bias in ecology and evolution: an empirical assessment using the 'trim and fill' method. Biological Reviews 77: 211-222.

Jormalainen, V., 1998. Precopulatory mate guarding in crustaceans: male competitive strategy and intersexual conflict. Quarterly Review of Biology 73: 275-304.

Koricheva, J., 2003. Non-significant results in ecology: a burden or a blessing in disguise? Oikos 102: 397-401.

Kvarnemo, C. \& I. Ahnesjö, 1996. The dynamics of operational sex ratios and competition for mates. Trends in Ecology and Evolution 11: 404-408.

Lefebvre, F. \& R. Poulin, 2005. Alternative reproductive strategies in the trematode Coitocaecum parvum: comparison of selfing and mating worms. Journal of Parasitology 91: 93-98.

Lopez, S., 1999. Parasitized female guppies do not prefer showy males. Animal Behaviour 57: 1129-1134.

MacFarlane, W. V., 1939. Life cycle of Coitocaecum anaspidis Hickman, a New Zealand digenetic trematode. Parasitology 31: 172-184.

McCahon, C. P. \& D. Pascoe, 1988. Increased sensitivity to cadmium of the freshwater amphipod Gammarus pulex (L.) during the reproductive period. Aquatic Toxicology 13: 183-194.

Minchella, D. J., 1985. Host life history variation in response to parasitism. Parasitology 90: 205-216.

Poulin, R., 1994. Mate choice decisions by parasitized female upland bullies Gobiomorphus breviceps. Proceedings of the Royal Society of London B 256: 183-187.

Poulin, R., 2001. Progenesis and reduced virulence as an alternative transmission strategy in a parasitic trematode. Parasitology 123: 623-630.

Poulin, R. \& W. L. Vickery, 1996. Parasite mediated sexual selection: just how choosy are parasitized females? Behavioral Ecology and Sociobiology 38: 43-49.
Poulton, M. J. \& D. J. Thompson, 1987. The effects of the acanthocephalan parasite Pomphorhynchus laevis on mate choice in Gammarus pulex. Animal Behaviour 35: 15771578.

Rumpus, A. E. \& C. R. Kennedy, 1974. The effect of the acanthocephalan Pomphorhynchus laevis upon the respiration of its intermediate host, Gammarus pulex. Parasitology 68: $271-284$.

Sokal, R. R. \& F. J. Rohlf, 1995. Biometry: The Principles and Practice of Statistics in Biological Research (3 rd). Freeman \& Co., New York.

Sutcliffe, D. W., 1992. Reproduction in Gammarus (Crustacea, Amphipoda): basic processes. Freshwater Forum 2: $102-128$.

Sutcliffe, D. W., 1993. Reproduction in Gammarus (Crustacea, Amphipoda): male strategies. Freshwater Forum 3: 97-109.

Thomas, F., A. Lambert, T. De Meeüs, F. Cézilly \& F. Renaud, 1995a. Influence of Microphallus hoffmanni (Trematoda, Microphallidae) on the survival, sexual selection, and fecundity of Gammarus aequicauda (Amphipoda). Canadian Journal of Zoology 73: 1634-1639.

Thomas, F., F. Renaud, J. M. Derothe, A. Lambert, T. De Meeüs \& F. Cézilly, 1995b. Assortative pairing in Gammarus insensibilis (Amphipoda) infected by a trematode parasite. Oecologia 104: 259-264.

Thomas, F., F. Renaud \& F. Cézilly, 1996. Assortative pairing by parasitic prevalence in Gammarus insensibilis (Amphipoda): patterns and processes. Animal Behaviour 52: 683-690.

Thomas, F., E. Oget, P. Gente, D. Desmots \& F. Renaud, 1999. Assortative pairing with respect to parasite load in the beetle Timarcha maritima (Chrysomelidae). Journal of Evolutionary Biology 12: 385-390.

Ward, P. I., 1984. The effects of size on the mating decisions of Gammarus pulex (Crustacea, Amphipoda). Zeitschrift für Tierpsychologie 64: 174-184.

Ward, P. I., 1986. A comparative field study of the breeding behaviour of a stream and pond population of Gammarus pulex (Amphipoda). Oikos 46: 29-36.

Zuk, M., 1992. The role of parasites in sexual selection: current evidence and future directions. Advances in the Study of Behavior 21: 39-68. 